\title{
The impact of culture on FDI disentangled: separating the "level" and the "distance" effects
}

\author{
Judit Kapás ${ }^{1}$ [D $\cdot$ Pál Czeglédi ${ }^{1}$
}

Received: 27 March 2019 / Accepted: 25 February 2020 / Published online: 5 March 2020

(c) The Author(s) 2020

\begin{abstract}
The most important concern of this paper centers on the question of whether the difference in inward FDI across countries is a result of the fact that destination countries have different cultures, or the fact that they are more distant culturally from the origin country than others? We argue that answering this question requires disentangling the impact of culture, which consists of separating two effects: the "level" (the former) and the "distance" effect (the latter), which are mixed in the literature, leading in this way to biased conclusions in relation to how cultural distance matters for FDI. In this paper we propose an econometric method to separate the two effects of the culture, in which the key is that cultural distance does not depend on the origin country's culture. Our empirical results indicate a "strong" level effect in the sense that it is a working effect in the case of all the three cultural values we use, and its size is economically significant, as well. The distance effect, however, is at best as important as the level effect but very probably less so, accordingly, it seems that the literature has "overemphasized" the impact of cultural distance.
\end{abstract}

Keywords FDI · Culture $\cdot$ Cultural distance $\cdot$ Institutions $\cdot$ Gravity model

JEL Classification $\mathrm{F} 21 \cdot \mathrm{F} 23 \cdot \mathrm{E} 02 \cdot \mathrm{Z} 10$

\section{Introduction}

During the last decade cultural explanations for foreign investments have been emerging and gaining ground. In the current state, however, this literature is still limited, not only in terms of the number of studies, but more importantly, regarding

Judit Kapás

judit.kapas@econ.unideb.hu

Pál Czeglédi

pal.czegledi@econ.unideb.hu

1 Institute of Economics, University of Debrecen, 138 Boszormenyi Street, 4032 Debrecen, Hungary 
the depth of our understanding of the impact culture exerts on foreign investments (for details see Sect. 2). The main concern of researchers in the field has been how cultural distance between the origin and the destination countries affect FDI. Although the findings of various empirical analyses on this issue are far from being unanimous, per se we do not find these controversial findings problematic; on the contrary, different cultural dimensions can be supposed to affect investors in different ways because "cultural difference does not always imply cultural conflicts" (Tang 2012: 249). The most important problem we do associate with this literature is that conclusions in relation to how cultural distance matters for FDI are, potentially, biased since the cultural distance measures used in the literature cannot be meaningfully compared across countries, a problem identified by van Hoorn and Maseland (2014). We argue accordingly, that the impact identified by the literature as arising from cultural distance is, in fact, a mixed impact of the cultural distance and the culture in the host country.

Cultural distance measures used in the literature are constructed by subtracting the origin and the host country scores on one or more cultural dimensions. ${ }^{1}$ The problem with these measures, as proved by van Hoorn and Maseland (2014), is that they correlate differently with the destination country's culture for each origin country, a problem which they refer to as the lack of the measurement equivalence in cultural distance. As a consequence, we cannot compare the impact of cultural distance on FDI for different origin countries when using the cultural distance measures in a way they are used in the literature.

The aim of this paper is to propose a possible solution to a meaningful comparison of the impact of cultural distance on FDI across countries even if we are driven to use the distance measures of the literature. ${ }^{2}$ The starting point in this endeavor is the recognition that the effect of cultural distance identified in the literature is in fact a mix of two effects: on the one hand a "level" effect, which means that a (different) culture in a given destination country as compared to that in another destination country might attract a different level of FDI, independently of the culture of the origin country; and on the other hand a "distance" effect, meaning that a (different) cultural distance between an origin country and a given destination country as compared to that between the same origin country and another destination country can induce different FDI flows, independently of the culture of the destination country.

In order to progress further in our understanding of the impact of culture on FDI, we argue that this mixed impact must be disentangled, which requires a separation of the above two effects of culture. In this paper we will propose an econometric method to separate the level and the distance effects of culture, which ensures at the same time that cultural distance does not depend on the origin country's culture, which is

\footnotetext{
1 A widely used measure was introduced in a seminal paper by Kogut and Singh (1988), in which they defined a composite cultural index based on Hofstede's (1980) cultural dimensions.

${ }^{2}$ In relation to the effect of institutional distance, van Hoorn and Maseland (2016) propose the use of multiple reference points instead of using the distance measures, a method which is hard to apply in regression analyses. Accordingly, we think that relying on the distance measures but designing the model in a novel way seems to be the best option to solve the measurement inequivalence problem. In addition, the main advantage of using the distance measures lies in the ease of their calculation.
} 
precisely van Hoorn and Maseland's (2014) condition for measurement equivalence in cultural distance.

We will integrate this method of disentangling the two effects into various regression estimations of an equation relying on the gravity framework to ensure the robustness of the results. Our panel dataset includes 31 OECD host countries and 52 destination countries for the period 2000-2013. When explaining FDI stocks, we will control for culture and formal institutions at the same time, a procedure which is not common in the literature, but which, on the theoretical side, is supported by the insight that formal institutions are embedded in culture (Boettke et al. 2008; Williamson 2000). Given that the above institutional economics theories on which we rely understand culture in terms of "deep" culture, as a proxy for culture we therefore need a cultural measure which intends to express culture in this "deep" sense. For our field of inquiry, the best choice is to use individual values scores from the Schwartz Values Survey (Schwartz 1999, 2006) because Schwartz sees individual values as the core of culture, to which formal institutions are stuck. We include one value item from all the three bipolar value dimensions (egalitarianism-hierarchy, embeddedness-autonomy, and harmony-mastery) determined by Schwartz (1999).

Our empirical results, besides confirming the findings of previous papers concerning the impacts of the "traditional" gravity variables, bring some new evidence as regards the impact of culture on foreign investments. First of all, we evidence that culture matters for FDI on its own, meaning that it affects foreign investments beyond formal institutions. Secondly, and more importantly, our empirical results indicate a very "strong" level effect in the sense that it is a working effect in the case of all the three cultural values and its size is economically significant, as well. The distance effect, however, is at best as important as the level effect but very probably less so; the equal importance of the two effects can be clearly supported only for mastery.

To sum up, our results for the OECD countries as origin countries have demonstrated that once we correctly separate the level and the distance effects of culture, the level effect proves to be more important. Thus it seems that the literature has "overemphasized" the impact of cultural distance due to the lack of measurement equivalence: what is deemed to be a distance effect in the literature is in fact not so, but a mixed effect of the level and the distance.

The rest of the paper is organized as follows. In Sect. 2 we will summarize the literature looking at the effects of culture (cultural distance) on FDI. Section 3 will present our econometric model which relies on the separation of the level and the distance effects of culture. We will explain our main variables and hypotheses in Sect. 4. The results of the empirical analyses will be discussed in Sect. 5. Section 6 will conclude.

\section{Review of the literature on the culture-FDI nexus}

As mentioned above, an analysis of the role of culture or cultural distance in attracting foreign investments is far from being in its maturity phase. ${ }^{3}$ The studies in the field differ in terms of whether they look at the impact of the culture in the

\footnotetext{
${ }^{3}$ For a detailed review of the literature on the culture-FDI link see Kapás (2020).
} 
destination country or that of the cultural distance between the origin and the destination country, whether they use a specific cultural dimension or a composite measure of culture, and whether they include in the regression formal institutions, as well as culture. Last but not least, scholars use different proxies for culture since they might adhere to a different concept of culture. ${ }^{4}$

Only a couple of studies deal with the impact of culture on FDI. Bhardwaj et al. (2007), for instance, examine the impact of two cultural variables, uncertainty avoidance (Hofstede 2001) and trust from the World Values Survey (WVS), and their interaction effect on FDI. The results confirm their hypotheses: a higher level of uncertainty avoidance is associated with lower inward FDI, and a higher level of trust is associated with greater inward FDI. Furthermore, the authors report that the effect of trust is reduced as the country's uncertainty avoidance increases.

Amongst the few papers including both culture and formal institutions at the same time in the analysis, Holmes et al. (2013), relying on the insight that culture shapes formal institutions, investigate the influence of culture [in-group collectivism and future orientation, taken from the GLOBE dataset (House et al. 2004)], on formal institutions, and then the effects of formal institutions on FDI inflows. The results indicate that formal institutions affect both culture and FDI, but there is no evidence that culture would influence FDI. Seyoum (2011) goes further into the issue of how culture and formal institutions affect inward FDI by exploring both the direct and indirect impact of culture on FDI, with the indirect impact of culture mediated via formal institutions. The cross-country regression results indicate on the one hand, that culture has a significant and greater effect on FDI than formal institutions, and on the other, that it affects FDI in an indirect way as well, which is mediated by formal institutions.

Studies focusing on the impact of cultural distance on FDI dominate the literature in the field. The majority of the studies find that larger cultural distance exerts a negative impact on FDI, but this result is not unanimous; Grosse and Trevino (1996) for instance do not document this negative effect for US inward FDI.

Tang's (2012) results are mixed for the cultural distance variables for all four of Hofstede's dimensions, defined as the net difference between source and host countries' scores. She demonstrates that different cultural dimensions affect FDI activities differently. More specifically, FDI has a U-shaped relationship with the net difference in individualism and an inverted U-shaped relationship with the net difference in power distance. When it comes to the net difference in uncertainty avoidance and masculinity, the impact is negative, that is, FDI increases when it flows from a low to a high uncertainty avoidance (or masculine) country. ${ }^{5}$

To our knowledge, Siegel et al. (2012) provide the most scrupulous analysis on how cultural distance affects FDI. Their conceptualization of culture comes from Schwartz's (1999) theory developed in cross-cultural psychology. As regards the mechanism via which cultural distance has an impact on FDI, Siegel et al. (2012)

\footnotetext{
4 There is a multitude of definitions of culture, whose summary is outside the scope of this paper. For a comprehensive review of the concepts of culture see Beugelsdijk and Maseland (2011).

5 For the reasons behind these findings see Tang's (2012) explanations.
} 
emphasize (uniquely) firm-level factors, most importantly the possible difficulty in interacting with stakeholders in the host country. Of Schwartz's three cultural dimensions they associate only one dimension (egalitarianism-hierarchy) and one of its polars (egalitarianism) with the above firm-level factor. In this spirit, their main hypothesis is that the greater the distance in terms of egalitarianism between the source and the host country, the greater the adjustments the multinational firm has to make to engage effectively with its stakeholders. The regression results based on gravity equations provide evidence for the significant negative link between cultural distance and FDI. The instrumental variable estimations reaffirm the main finding.

The focus of Lucke and Eichler (2016) is on whether foreign investors invest differently in developed versus developing and transition economies. On a panel of 29 source and 65 host countries for the period 1995-2009 they find that investors prefer to invest in developed countries with less or similar cultural diversity than their own, and they are deterred by larger cultural distance. When it comes to developing countries as source countries, foreign investors tend to invest more in less diverse countries than their own, and they are attracted by large cultural distance. ${ }^{6}$

Slangen and Beugelsdijk (2010) is unique in the literature in asking which hazards (cultural or institutional) affect which type of FDI (horizontal or vertical) to a greater extent. The main result is that both hazards related to formal institutions and cultural distance exert a greater impact on vertical FDI than on horizontal FDI. Furthermore, the impact of institutions is greater for both types of FDI than that of cultural distance.

To our knowledge, the only investigation addressing the issue of the interplay of institutions and cultural distance is Du et al. (2012). The paper analyzes how cultural distance from six countries affects their FDI to various Chinese mainland regions with different institutional quality. As the authors argue, cultural proximity may play an important role in mitigating the negative impact of poor institutions on FDI. The results show that FDI coming from a country that is more culturally different from China exhibits higher sensitivity towards regional economic institutions in the FDI location choice.

\section{Disentangling the impact of culture, and the model}

The above review suggests that the findings of the literature as regards how cultural distance affects FDI are not converging to one single conclusion, which we find obvious since various cultural dimensions can exert different impacts and can work via different channels. What we do find problematic, however, is the inappropriate

\footnotetext{
${ }^{6}$ Another paper looking at the question of whether culture's impact on FDI is equally relevant for all countries is Mondolo (2019) which, by using a meta probit model, finds that culture in attracting FDI is mainly important for developing countries as destination countries. Note, however, that Mondolo's (2019) procedure to consider corruption an informal institution (culture) goes against the view of the institutional economics literature, which weakens the author's argument for our concern.
} 
treatment of cultural distance in the regression analysis, which, in our view, leads to biased results concerning its impact on FDI.

While, as we argue, the problem is manifested in an inappropriate economic specification of the models used by various researchers, the root problem is the failure of the recognition that at theoretical level there are two effects of culture. On the one hand, a (different) culture in a given destination country as compared to that in another destination country might attract a different level of FDI, independently of the culture of the origin country, an effect we call the "level" effect. On the other hand, a (different) cultural distance between an origin and a given destination country as compared to that between the same origin country and another destination country can induce different FDI, independently of the culture of the destination country, an effect we call the "distance" effect. In reality, these two effects work at the same time and are manifested in one effect. Note that what the literature we reviewed above examines is simply this manifested effect of culture, which is claimed to be the effect of cultural distance, but in fact, as we will prove in what follows this is a mixed impact of the level and the distance effects.

In our view the lack of distinction of the level and the distance effects of culture is nothing but a manifestation of the lack of the measurement equivalence in cultural distance, a problem identified by van Hoorn and Maseland (2014). As the two scholars explain, the measurement equivalence in cultural distance would require that the cultural distance measures exhibit cross-culturally consistent relationships with other country factors, but they prove that the cultural distance measures correlate differently with the destination country culture for each origin country. This means that including the cultural distance measure in regressions equalizes, to take their example, the cultural distance of the partner countries from Belgium with those from the USA, which leads to biased effects of the cultural distance. What we have to do is compare the cultural distance from Belgium with Belgian outward FDI and the cultural distance from the USA with USA outward FDI.

Bearing these problems in mind, we argue for disentangling the level and the distance effects of the culture; therefore, we propose an econometric method to separate these two effects, which allows us to specify our model in an appropriate way. The mathematical derivation of the separation of the two effects of culture, and the resulting econometric specification are presented in the "Appendix".

As usual in the literature, in our empirical investigations we will rely on the gravity model framework ${ }^{7}$; and assuming a panel setting with a random effects model our specification based on Eq. (16) in the "Appendix" is the following:

$$
\begin{aligned}
\mathrm{fdi}_{\mathrm{ijt}}= & \mathbf{X}_{1 \mathrm{it}} \boldsymbol{\beta}_{1}+\mathbf{X}_{2 \mathrm{jt}} \boldsymbol{\beta}_{2}+\mathbf{X}_{3 \mathrm{ijt}} \boldsymbol{\beta}_{3}+\beta_{4} \text { inst }_{\mathrm{jt}}+\beta_{5} \text { ncd }_{\mathrm{ij}} \times\left(\text { cult }_{\mathrm{j}}-\text { cult }_{\mathrm{i}}\right)+\beta_{6} \mathrm{pcd}_{\mathrm{ij}} \\
& \times\left(\text { cult }_{\mathrm{j}}-\text { cult }_{\mathrm{i}}\right)+\beta_{7 \mathrm{i}} \mathrm{d}_{\mathrm{i}}+\beta_{8} \mathrm{~d}_{\mathrm{t}}+\alpha_{\mathrm{ij}}+u_{\mathrm{ijt}}
\end{aligned}
$$

where $\mathrm{i}$ denotes the country of origin, $\mathrm{j}$ is the destination country, $f d i_{i j t}$ is the $\log$ of outward FDI stocks from origin country $\mathrm{i}$ to destination country $\mathrm{j}$ in year $\mathrm{t}$, cult $_{i}$

\footnotetext{
7 The gravity model framework was designed originally for an analysis of international bilateral trade, but extended later to that of FDI flows as the baseline model.
} 
is a measure of culture in the origin country, cult $t_{j}$ is a measure of culture in the destination country, $d_{i}$ is an origin country dummy, $d_{t}$ is a year dummy, and $\alpha_{i j}$ is country-pair specific random effect. The vector variables $\boldsymbol{X}_{1 \mathrm{it}}, \boldsymbol{X}_{2 \mathrm{jt}}, \boldsymbol{X}_{3 \mathrm{ijt}}$ include the "traditional" variables from the gravity model: $\boldsymbol{X}_{1 \mathrm{it}}$ and $\boldsymbol{X}_{2 \mathrm{jt}}$ include, respectively, the variables specific for the origin (i) and for the destination (j) country, while $\boldsymbol{X}_{3 \mathrm{ijt}}$ denotes the bilateral variables. Two dummy variables, $n c d_{i j}$ (if cult $\mathrm{i}_{\mathrm{i}}>$ cult $_{\mathrm{j}}$ ) and $p c d_{i j}$ (if cult $_{j} \geq$ cult $_{i}$ ) account for a negative and a positive cultural distance, respectively.

We control for the formal institutions in the destination country (inst $t_{j}$ ), at the same time, which is the recognition of the fact that culture and institutions influence FDI simultaneously. The theoretical reason behind this argument arises from the theory of institutional stickiness (Boettke et al. 2008), and the hierarchy of institutions (Williamson 2000), both suggesting that formal institutions are embedded in culture.

As shown in the "Appendix" (Eqs. 22 and 23), this specification allows us to disentangle the level and the distance effects of culture with the help of the coefficients $\beta_{5}$ and $\beta_{6}$ in Eq. (1):

$$
\begin{aligned}
& \beta_{\text {lev }}=\frac{1}{2}\left(\beta_{5}+\beta_{6}\right) \\
& \beta_{\text {dist }}=\frac{1}{2}\left(\beta_{6}-\beta_{5}\right)
\end{aligned}
$$

To clearly understand how the distance and the level effects are always mixed in some combination in reality, let us consider two destination countries, country1 and country2, that are similar in every respect but different with respect to their culture ( cult $_{1}<$ cult $_{2}$ ), and country1 is culturally closer to a given origin country. There are two reasons why the two destination countries may attract different levels of FDI. One is the fact that country 2 is placed higher on the scale of culture than country1 ( cult $_{2}>$ cult $\left._{1}\right)$, which is the level effect; and the second is that country1 is closer culturally to the origin country than is country 2 $\left(\right.$ cult $_{2}-$ cult $_{\mathrm{i}}>$ cult $_{\mathrm{i}}-$ cult $\left._{1}\right)$, which is the distance effect. Mathematically, the difference in FDI between country2 and country1, according to Eq. (1) is.

$$
\begin{aligned}
& \mathrm{fdi}_{\mathrm{i} 2}-\mathrm{fdi}_{\mathrm{i} 1}=\beta_{6}\left(\text { cult }_{2}-\text { cult }_{i}\right)-\beta_{5}\left(\text { cult }_{1}-\text { cult }_{i}\right)=\beta_{6}\left(\text { cult }_{2}-\text { cult }_{i}\right)+\beta_{5}\left(\text { cult }_{i}-\text { cult }_{1}\right) \\
& \quad=\beta_{\text {lev }}\left(\text { cult }_{2}-\text { cult }_{1}\right)+\beta_{\text {dist }}\left[\left(\text { cult }_{2}-\text { cult }_{i}\right)-\left(\text { cult }_{i}-\text { cult }_{1}\right)\right],
\end{aligned}
$$

because the definitions in Eqs. 2 and 3 imply that $\beta_{5}=\beta_{\text {lev }}-\beta_{\text {dist }}$ and $\beta_{6}=\beta_{\text {lev }}+\beta_{\text {dist }}$. Since both the level and the distance effect can be zero, negative or positive, we have nine possible combinations of the two effects as listed in Table 1, which we will use when interpreting our regression results.

To see why the studies we reviewed document biased results concerning the effect of cultural distance, let us consider the econometric specification of these studies:

$$
\mathrm{fdi}_{\mathrm{ij}}=\boldsymbol{\gamma}^{\prime} \mathbf{X}+\gamma_{5} \mid \text { cult }_{i}-\text { cult }_{j} \mid+\gamma_{6 \mathrm{i}} \mathrm{d}_{\mathrm{i}}
$$


Table 1 Possible values of $\beta_{5}$ and $\beta_{6}$, and their interpretations

\begin{tabular}{llllll}
\hline Case & Sign of $\beta_{5}$ & Sign of $\beta_{6}$ & Relation between $\beta_{5}$ and $\beta_{6}$ & $\begin{array}{l}\text { Implied sign } \\
\text { of } \beta_{\text {lev }}\end{array}$ & $\begin{array}{l}\text { Implied } \\
\text { sign of } \\
\beta_{\text {dist }}\end{array}$ \\
\hline 1 & + & + & $\beta_{5}=\beta_{6}$ & + & 0 \\
2 & + & $-/ 0 /+$ & $-\beta_{5}<\beta_{6}<\beta_{5}$ & + & - \\
3 & + & - & $\beta_{6}=-\beta_{5}$ & 0 & - \\
4 & $-/ 0 /+$ & + & $-\beta_{6}<\beta_{5}<\beta_{6}$ & + & + \\
5 & $-/ 0 /+$ & - & $\beta_{6}<\beta_{5}<-\beta_{6}$ & + & - \\
6 & - & + & $\beta_{6}=-\beta_{5}$ & 0 & - \\
7 & - & $-/ 0 /+$ & $\beta_{5}<\beta_{6}<-\beta_{5}$ & - & + \\
8 & - & - & $\beta_{5}=\beta_{6}$ & - & 0 \\
9 & 0 & 0 & $\beta_{5}=\beta_{6}$ & 0 & 0 \\
\hline
\end{tabular}

Scholars interpret $\gamma_{5}$ as the coefficient for cultural distance, which is a mistake for the following reason. By taking cult $\mathrm{i}_{\mathrm{i}}$ as given, $\gamma_{5}=\frac{\partial \mathrm{ddi}_{\mathrm{ij}}}{\partial \mid \text { cult }_{\mathrm{i}}-\text { cult }_{\mathrm{j}} \mid}= \pm \frac{\partial \mathrm{fdi}_{\mathrm{ij}}}{\partial \text { cult }_{\mathrm{j}}}$, with the sign depending on whether cult $_{\mathrm{i}} \geq$ cult $_{\mathrm{j}}$ or not. But $\frac{\partial \mathrm{fdi}_{\mathrm{ij}}}{\partial \text { cult }_{\mathrm{j}}}$ itself, as shown in the "Appendix", "includes" both the distance and the effect level. ${ }^{8}$

\section{Variables, data, and hypotheses}

Table 7 in the "Appendix" contains all the variables we use to estimate our Eq. (1), their sources and their names in our model. We will not discuss here those variables that are widely used in the FDI-culture literature. But the choice for our main independent variables expressing formal institutions and culture requires justification because these variables are used in a wide variety in the relevant literature.

As for institutions, a number of studies highlight the role of various institutions in encouraging FDI. The results of different scholars have been converging to show the significant impact of the following institutions: (1) corruption (e.g., Habib and Zurawicki 2002; Barassi and Zhou 2012), (2) governance and regulatory institutions (e.g., Globerman and Shapiro 2002; Daude and Stein 2007; Bénassy-Quéré et al. 2007; Kurul 2017), (3) secure property rights (e.g., Ali et al. 2010; Li and Resnick 2003), (4) political institutions (civil and political rights)

\footnotetext{
${ }^{8}$ The only paper whose specification can be paralleled with ours is Siegel et al. (2012) which includes cultural distance in two forms, namely sheer (the square of the difference between the host and source country egalitarianism) and directional (with a positive or negative sign) in their regression. However, what they actually do is to separate the two effects of culture, but they fail to interpret their results in this way; instead they claim that they answer the question of whether the effect of the distance is different if it is the destination country, not the origin country, where culture is "better". Our mathematical proof is available upon request.
} 
(e.g., Busse 2004; Asiedu and Lien 2011), and (5) political risk (e.g., Busse and Hefeker 2007).

When selecting our institutional variables we rely on these results, namely we use governance and regulatory institutions, corruption and political risk. For econometric reasons, it is best to incorporate a composite measure of formal institutions in the regressions since including several institutions at the same time raises the problem of multicollinearity; and including them one by one might lead to an omitted variables bias. The usual way to reduce dimensions is to calculate the first principal component from a principal component analysis. In this spirit, to derive our measure for formal institutions we use three widely used datasets: the World Governance Indicators of the World Bank, the International Country Risk Guide, and the Economic Freedom of the World Index. The first principal component is derived for all years between 2000 and 2013 except for 2001 for which the WGI data are not available. Our first principal component explains more than $80 \%$ of the total variance for each of the twelve years considered, and its eigenvalue is above six in every case.

The other key independent variable is a measure of culture. There is a multitude of concepts of culture in the literature, amongst which we stick with the one which understands culture as values of people, reflecting the most basic norms, judgments, and beliefs in relation to how to interact with and behave towards other people, transmitted from generation to generation. In this meaning cultural values can be seen as external and unalterable conditions on individuals. We have two reasons for relying on this conceptualization; one comes from the theoretical considerations we have behind our model, and the other is related to econometrics.

On the theoretical side, clearly, in our model the conceptualization of culture has to be in line with that of formal institutions. This conceptual link between formal institutions and culture, we think, is established in the theory of institutional stickiness (Boettke et al. 2008) which suggests that formal institutions are stuck to what the authors call metis $^{9}$ which is thought to consist of those values that are to a large extent exogenous to people, comprising unwritten (informal) norms, practices, beliefs, and conventions in the field of people's interactions. Metis constitutes a core onto which formal institutions are stuck. In our understanding metis is nothing other than the "deepest" cultural layer, consisting of values. When relying on the above concept of culture, we adhere to the emerging view in the literature which argues that culture has several dimensions (e.g., Klasing 2013); and that the effects of various cultural dimensions must be analyzed separately from one another (Durlauf and Fafchamps 2005) to see the potentially different effects produced.

On the side of econometrics, an understanding of culture in terms of values, we think, offers the advantage of minimizing multicollinearity in regression analysis. Recall that we will control in our regression analysis both for formal institutions and culture. Relying on a concept of culture which is exogenous to the developmental process can serve this aim, since in this case culture is not assumed to be adjusted to formal institutions, leading to a lower correlation between our measures for culture

\footnotetext{
${ }^{9}$ Metis is a Greek word, and means wisdom or skill.
} 
Table 2 Individual values and their meanings (Source: based on Schwartz (1999))

\begin{tabular}{ll}
\hline Bipolar values & Meaning \\
\hline $\begin{array}{l}\text { Embeddedness-auton- } \\
\text { omy (affective/intel- } \\
\text { lectual) }\end{array}$ & $\begin{array}{r}\text { In societies characterized by a high degree of embeddedness, individuals are } \\
\text { embedded in the group, and expected to restrain actions that might disrupt } \\
\text { the solidarity of the group or the traditional order } \\
\text { In (intellectually and affectively) autonomous societies, individuals can act } \\
\text { independently, and pursue their own interests and goals }\end{array}$ \\
$\begin{array}{l}\text { In highly hierarchical societies, there is an unequal distribution of power, } \\
\text { roles and resources } \\
\text { In egalitarian societies collective action is achieved by voluntary cooperation } \\
\text { of individuals who see themselves as equals } \\
\text { Mastery stresses an emphasis on assertiveness and ambition in order to mas- } \\
\text { ter the environment and reach personal and group goals } \\
\text { Harmony stresses the acceptance of the environment as it is and the impor- } \\
\text { tance of its preservation }\end{array}$ \\
\hline
\end{tabular}

and formal institutions as opposed to a correlation between institutions and an "adjustable" component of culture, such as trust. ${ }^{10}$

To express culture in terms of values, the best dataset is the Schwartz Values Survey (Schwartz 1999, 2006). Since individual values are assumed to be relatively time-invariant we include as many observations as possible taken from all the waves of the survey, and take the mean of the scores for the cultural values we use for each country.

An advantage of this dataset vis-à-vis the other cultural databases (e.g., Hofstede 2001, WVS) is that the survey questions and the variables derived from them rely on a priori theorizing. ${ }^{11}$ The starting point for Schwartz $(1999,2006)$ is that all societies confront three basic issues when forming social relations, and the answers to these questions are inherently different in different societies. Based on these, he identifies seven value types, forming three bipolar value dimensions, namely egalitarianism-hierarchy, embeddedness-autonomy, and harmony-mastery. ${ }^{12}$ Table 2 explains the meaning of the seven values.

Since there are two value types alongside the three dimensions, we do not need to use all the seven values, just one from every dimension. Hypotheses about which cultural value affects FDI, and in what way can be formulated based on Table 2. Before doing that we need to clearly argue that culture influences foreign investors through firm-level factors, as suggested unanimously by the literature (see for instance Siegel et al. 2012 or Tang 2012). Accordingly, we should look at which value is supposed to exercise a straightforward impact on firm-level decisions about investments abroad, and why. On the other hand, recall that in our analysis the unit is a country pair. Accordingly, when hypothesizing about the level effect we should "fix" the origin country and look at whether a destination country with higher cultural value will attract more or less FDI than another with lower cultural value. When it comes to the distance effect, we should determine whether a destination

${ }^{10}$ Trust is found to be endogenous in economic development in, for instance, Tabellini (2010).

${ }^{11}$ See Siegel et al. (2012) for more reasons why the Schwartz dataset is superior to its competitors.

12 Autonomy is divided into two types. 
country that is culturally closer is more attractive than another that is culturally farther from a given origin country.

Concerning the embeddedness-autonomy value pair, we posit that embeddedness is related to the ease and cost of rule compliance in the destination country. Higher embeddedness can be favorable for foreign firms to operate in the destination country since in a high-embeddedness society people are supposed to comply with rules "imposed" on them to a greater extent than in a low-embeddedness society. Accordingly, foreign investors may find it attractive to work with people who are ready to comply with the "rules" of the company. When it comes to the egalitarianism-hierarchy pair, we follow Siegel et al. (2012) who argue that egalitarianism affects the way in which multinational firms can adjust to engage with their foreign stakeholders: a higher level of egalitarianism can make it easier and less costly to cooperate with employees, suppliers etc. since higher egalitarianism leads to better cooperation. Of the harmony-mastery value pair we choose mastery because we can assume that foreign firms prefer countries where stakeholders put great emphasis on reaching the goals of the company, and behaving in an entrepreneurial way to provide solutions to various problems.

To sum up, for each value we hypothesize a positive level effect: a destination country with "better" values is more attractive than another with worse values. We also posit that this effect should be important in size since, based on the above explained working mechanisms, foreign investors per se find themselves better off in a country in which these values are better. However, when it comes to the distance effect, very probably foreign investors will invest more in that destination country in which the cultural values are closer to the home level as opposed to those destination countries whose cultural distance is farther, since they have developed practices, norms, and rules based on the home level of values. Lower distance means less potential conflict for them. We might assume, however, that even if this effect occurs, it will be less important in size than the level effect.

To sum up, we will use three cultural variables, namely embeddedness, egalitarianism, and mastery. Since we are interested in separating their level and the distance effect, we will analyze their impacts separately. ${ }^{13}$

\section{Empirical analysis}

For our field of inquiry, based on our data structure, the use of both cross-section (with variables averaged over the period 2000-2012) and panel regressions can be justified. Although cross-section investigations are very frequently used in gravity models, they do not make use of all information we have. Pooled regressions make some use of the panel structure of the data but assume that within-country-pair observations are as independent as cross country-pair observations, which, indeed, does not seem to be a plausible assumption. For this reason and since a number of independent variables, including the cultural variables we are focusing on, are

\footnotetext{
13 The correlations between the Schwartzian cultural variables are shown in Table 8 of the Appendix, which suggests that using them separately is a meaningful idea.
} 
time-invariant and country- or country-pair-specific, we will estimate our equation with a random effects model besides cross-section approach.

To account for the usual potential problems associated with institutions in regression, we will apply instrumental variables techniques as well for each method. Institutions may easily be endogenous in the FDI-institutions nexus because, on the one hand, the competition between governments to attract more FDI might make them improve some elements of their formal institutions, and on the other, countries which attract more FDI can be pressured to improve their institutions by the multinational firms present in the country. However, as we have good reasons to assume the exogeneity of our cultural variables, we do not need to instrument them. ${ }^{14}$

The potential candidates for an instrument for formal institutions are numerous since the literature has provided us with several variables that are good predictors of institutions. Of these, we have chosen English legal origin (La Porta et al. 2008) which, besides fulfilling the social science requirements vis-à-vis an instrument, meets the formal requirements, namely being correlated with the endogenous variables and being uncorrelated with the error term, too.

So, at the end of the day, we will run cross-section OLS and IV, and random effects and random effects IV regressions. We do not choose a priori among them; rather we will apply all of them, with the aim of selecting — on the basis of various econometrics tests and/or the plausibility of the results - the most appropriate one, and consider the others as robustness checks. ${ }^{15}$ The results are shown in Tables 3 and 4, and descriptive statistics for our variables are given in Table 9 of the "Appendix".

Tables 3 and 4 have four panels. The first panel includes the basic specifications, which is the one with only the "traditional" gravity variables, and another that adds institutions to this. In the remaining three panels we add our three cultural variables separately, that is, embeddedness, egalitarianism and mastery, respectively.

In both tables we have run the regressions for the same sample (the same number of observations) to make sure that results will be comparable across specifications. The main constraint on the number of observations has been data on the cultural variables. Although the cross-section sample is derived from the panel dataset by taking averages, the number of country-pairs is not the same as in the panel dataset (1317 versus 1296). The reason for this is that some variables must have been averaged by country-pairs while others by country, and the averaging by country sometimes "fills" the observations that are lacking when the data is organized in a panel.

\subsection{Baseline specifications results}

The "traditional" gravity variables in the first baseline specification (column 1 in Tables 3 and 4), by using all the three techniques, are proved to behave as expected. A country with a higher GDP will send more FDI provided that its population is

\footnotetext{
${ }^{14}$ Note that the Schwartzian understanding of cultural values of which we use embeddedness, egalitarianism and mastery conceptualizes them as external and unalterable conditions on humans, as mentioned above.

${ }^{15}$ As additional robustness checks we have run pooled OLS and IV regressions as well, whose results are available upon request.
} 


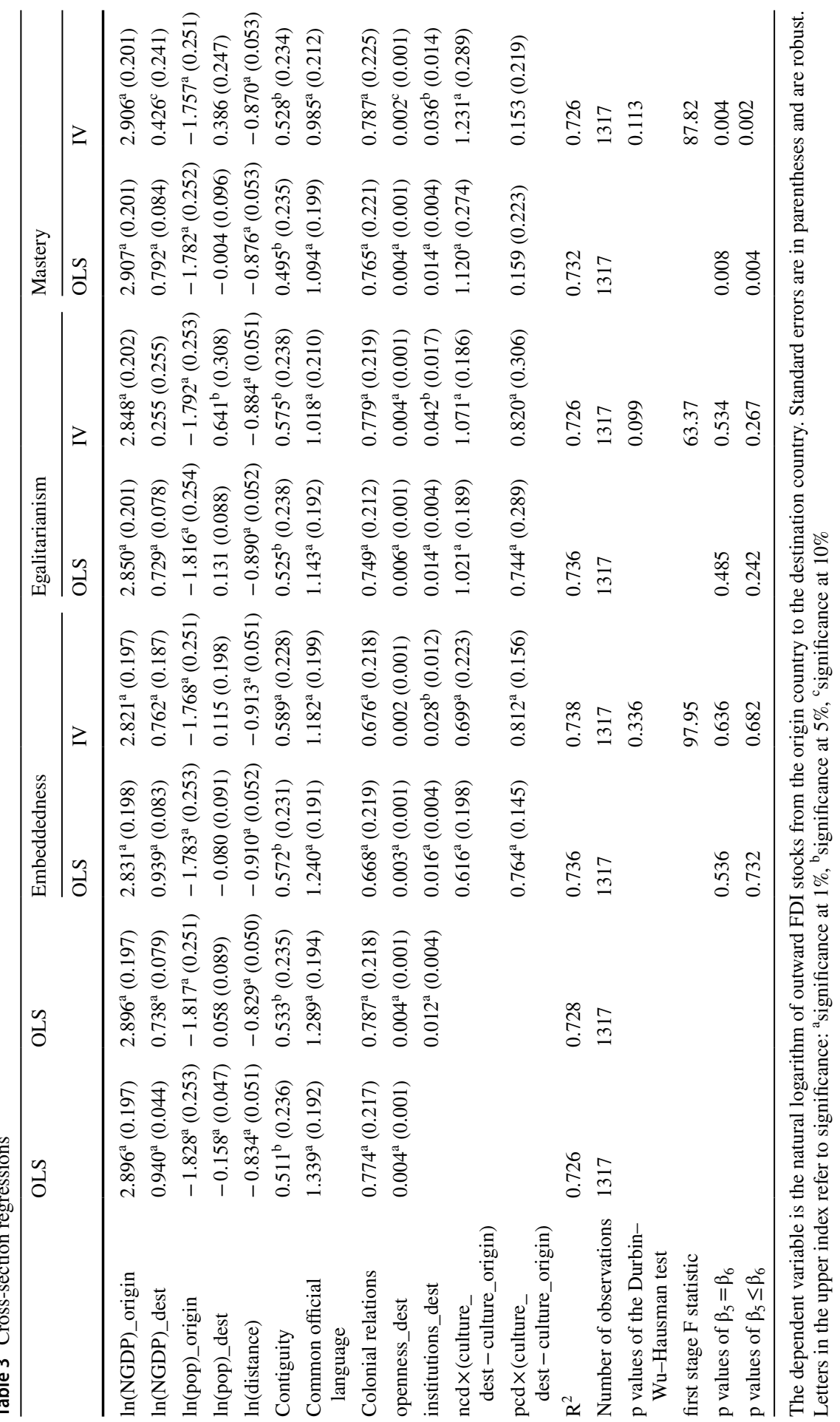




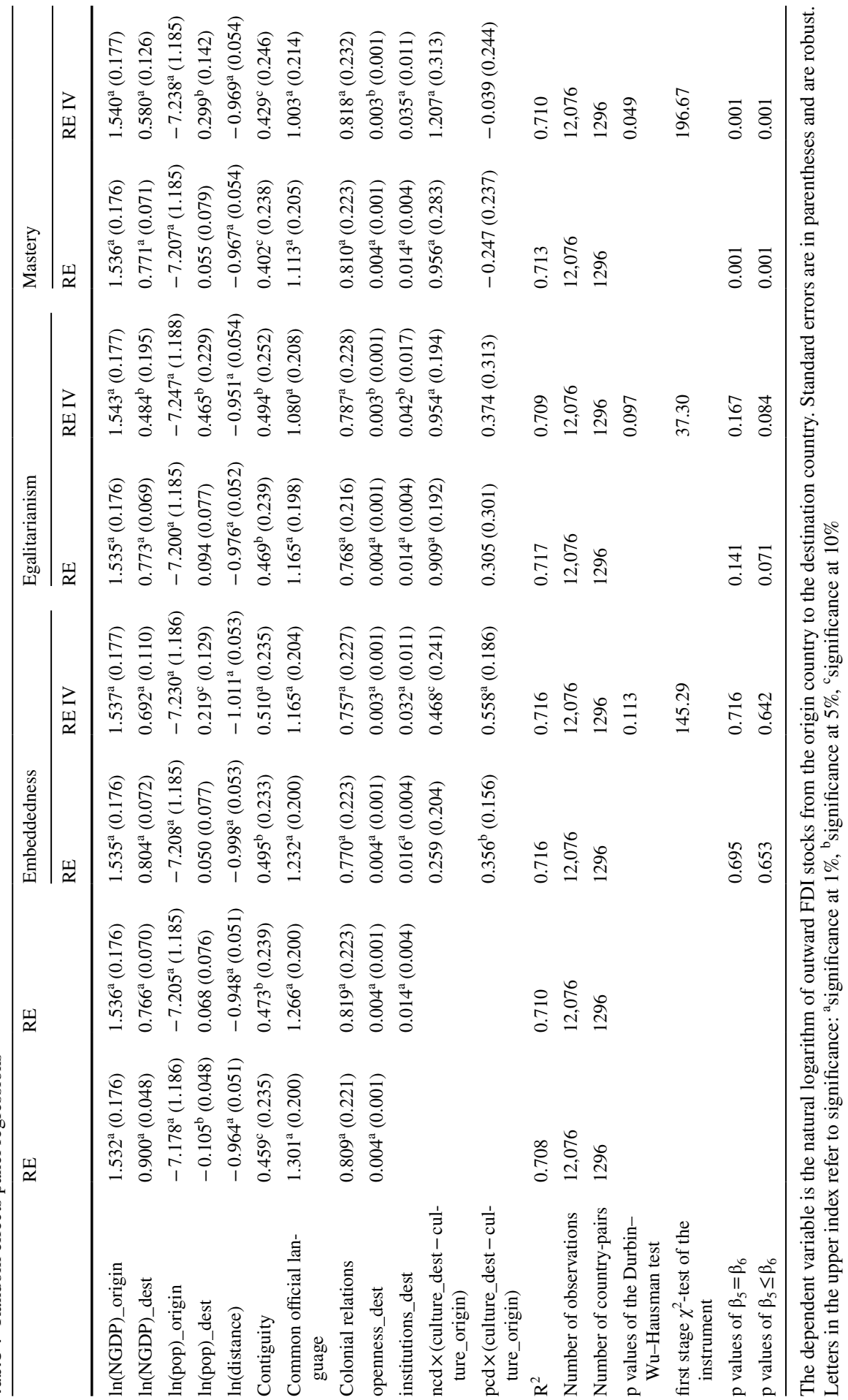


held constant, while population has the opposite effect. This seems to show that rich countries (in terms of per capita GDP) invest more in other countries than poorer ones. The signs of these two variables are the same for the destination country, too, meaning that countries with a higher GDP and the same population receive more FDI, whereas countries with a higher population but the same GDP receive less. This interpretation is strengthened by the fact that the population of the destination country loses its significance once institutions of the host country are included (column 2 in Tables 3 and 4). The reason may be that institutions are a good predictor of per capita GDP, and the effect of per capita GDP is the only reason why the population of the host country turns out to be a significant factor. Total nominal GDP does not lose its significance, perhaps because it is not only real per capita GDP through which it affects FDI.

The coefficients of all the bilateral "traditional" variables have the sign which could be expected: being closer to each other geographically, being contiguous, having a common official language, and having been in a colonial relationship predicts that the origin country will send more FDI to the partner country. All these results are perfectly in line with the findings of the papers analyzing the role of institutions in a gravity model (e.g., Daude and Stein 2007). In addition, with all methods the explanatory power of the model is very high (the $\mathrm{R}^{2}$ is 0.710 and 0.728 for the second columns).

\subsection{Results with the cultural variables}

Our focus in analyzing the results concerning the cultural variables as interacted with the ncd and pcd dummies is first of all the size of the coefficients and their statistical significance. Second, in accordance with what has been explained in Sect. 3 we are interested in the relation between $\beta_{5}$ and $\beta_{6}$. As a formal test we included the $\mathrm{p}$ values of the null hypothesis of their equality as well as their inequality in the last two rows of Tables 3 and 4. In what follows we will discuss the results from the application of cross-section and random effects regressions, including the ones in which the variable for formal institutions is instrumented. To indicate the reasonableness of instrumenting, we also insert the $p$ values of the Durbin-Watson-Hausman test. F- and Chi squared statistics of the instrument in the first stage regression are also reported to show that the instrument is not weak.

\subsubsection{Cross-section regressions}

Table 3 shows the result for simple OLS and instrumental variables regressions as run on our cross-section of country-pairs. It seems that the three cultural variables do not behave in exactly the same way. Based on Table 1 we can determine for all the three cultural variables which effect is working and in which direction.

For embeddedness, although the estimated value of $\beta_{5}$ is smaller than that of $\beta_{6}$, the hypothesis of their equality cannot be rejected at the usual significance levels. But even treating them as different will lead to estimating a small (but 
positive) distance effect. That is, the results are in line with either case 1 in Table 1 or case 4 with a (positive) distance effect of one tenth of the level effect.

As for egalitarianism, the equality of the two betas cannot be rejected at the $10 \%$ level in either case. However, the difference of the estimated values of the two betas predicts a somewhat bigger and negative distance effect for egalitarianism than for embeddedness. Based on the formal tests, then, egalitarianism corresponds to either case 1 in Table 1 or to case 2 with a (negative) distance effect of the size of a sixth of the level effect.

Results with mastery are much clearer. The equality of the two betas can clearly be rejected, which is no surprise once $\beta_{6}$ is estimated to be insignificantly different from zero. The effect of mastery is therefore in line with case 2 of Table 1 with the distance effect equal to the level effect.

\subsubsection{Random effects regressions}

The results from the RE and RE IV estimation, which can be found in Table 4, indicate somewhat larger distance effects for embeddedness than does the cross-section method above. $\beta_{5}$ is estimated to be insignificantly different form zero in the simple RE case (the relevant one, the institutional variable being exogenous) which allows us to conclude that there is a positive distance effect whose size is equal to the that of the level effect. Although the formal test does not reject the equality of the two betas in interest, the best guess seems to be that these results are in line with case 4 in Table 1 .

For egalitarianism, the RE and the RE IV estimations of $\beta_{6}$ are statistically insignificantly different form zero, while the estimation of $\beta_{5}$ is significantly positive. This means that the distance effect is relatively larger (and negative) now. The hypothesis that $\beta_{5}<\beta_{6}$ can also be rejected at the $10 \%$ significance level, as can the exogeneity of the formal institutions variable, which makes case 2 of Table 1 the best description of the effect of egalitarianism while noting further that the negative distance effect in this case seems almost as large as the positive level effect.

As for mastery, the presence of a negative distance effect combined with a positive and equally large level effect is supported again. Judging by the IV results, the formal institutions variable being endogenous, the two effects would be roughly equal even if we used the estimated value of $\beta_{6}$, making case 2 of Table 1 still the best description of the effect of mastery.

\subsection{Summary and interpretation of the results}

Our results based on the cross-section (OLS and IV), and RE and RE IV regressions are summarized in Table 5, from which we can draw two conclusions.

First, the three cultural values work in a similar way as regards the effect of the level of culture: a higher level of embeddedness, egalitarianism and mastery in the destination country has been shown to attract more FDI, independently of the culture of the origin country. This is because a higher level of all the three cultural values makes foreign investors feel more comfortable when cooperating with the stakeholders of the company in the destination country, and this cooperation comes at a 
Table 5 Summary of the regression results

\begin{tabular}{lllll}
\hline Cultural dimension & Estimation method & \multicolumn{2}{l}{$\begin{array}{l}\text { Relation between the } \\
\text { coefficients }\end{array}$} & \multicolumn{2}{c}{ Conclusion on cultural } \\
\cline { 5 - 5 } Embeddedness & Cross-section OLS & $\beta_{5}=\beta_{6}>0$ & 0 & Level \\
& Cross-section IV & $\beta_{5}=\beta_{6}>0$ & 0 & + \\
& RE & $\beta_{6}>\beta_{5}=0$ & + & + \\
& RE IV & $\beta_{5}=\beta_{6}>0$ & 0 & + \\
Egalitarianism & Cross-section OLS & $\beta_{5}=\beta_{6}>0$ & 0 & + \\
& Cross-section IV & $\beta_{5}=\beta_{6}>0$ & 0 & + \\
& RE & $\beta_{5}>\beta_{6}=0$ & - & + \\
Mastery & RE IV & $\beta_{5}>\beta_{6}=0$ & - & + \\
& Cross-section OLS & $\beta_{5}>\beta_{6}=0$ & - & + \\
& Cross-section IV & $\beta_{5}>\beta_{6}=0$ & - & + \\
& RE & $\beta_{5}>\beta_{6}=0$ & - & + \\
& RE IV & $\beta_{5}>\beta_{6}=0$ & - & + \\
\hline
\end{tabular}

lower cost. It seems that what we have hypothesized in Sect. 4 as regards why these cultural values will have a positive impact on FDI is working.

Second, the three cultural values work differently as regards the impact of cultural distance. Embeddedness has no or a positive distance effect. It is more difficult to decide whether egalitarianism has a distance effect as different estimations give somewhat different results. Considering the RE method our preferred method (see below), we conclude that egalitarianism has a negative distance effect. The case of mastery is easier because all the results point in the same direction: the distance effect is as large as the level effect but negative.

To make the above arguments clearer, as a next step, we will calculate the size of the level and the distance effects, by relying on our estimations. We use the IV estimation in those cases in which the Durbin-Watson-Hausman tests indicate that the IV estimations are the consistent ones at the $10 \%$ significance level. The cross-section estimations are seen as the default in the literature, therefore we consider them robustness checks for our results, by preferring the RE method because it makes use of the panel structure of the data. ${ }^{16}$

Standardized level and distance effects for our three cultural values are summarized in Table 6, taking statistically insignificantly non-zero coefficients as zero. As shown by the RE columns of the table, one standard deviation change ${ }^{17}$ in

\footnotetext{
${ }^{16}$ Note that we prefer the RE estimations to the pooled OLS ones, too, for three reasons. First, the results from the RE estimations compliment those from the cross-section OLS ones better than would those from the pooled OLS, since the RE approach is more radically different. Second, the BreuschPagan test allows us in every case to reject the hypothesis that a pooled OLS estimation may be appropriate. Third, as Plümper and Troeger (2007: 217) show, an RE model is, under broad conditions, more efficient than the pooled OLS model.

17 Of course, the measure of culture we use is time-invariant, that is, it can neither increase nor decrease. It is more convenient, however, to talk about the regression results in terms of its "change" than in terms of positive or negative difference between two pairs of countries. We always mean the latter when we use the terms "change", "increase" or "decrease" with regard to culture.
} 
Table 6 Standardized level and distance effects from the random effects and cross-section regressions

\begin{tabular}{|c|c|c|c|c|c|c|c|c|}
\hline \multirow[t]{3}{*}{ Cultural value } & \multicolumn{4}{|c|}{ Standardized betas } & \multirow{2}{*}{\multicolumn{2}{|c|}{$\frac{\text { Level effect }}{\beta_{\text {lev }}}$}} & \multirow{2}{*}{\multicolumn{2}{|c|}{$\frac{\text { Distance effect }}{\beta_{\text {dist }}}$}} \\
\hline & \multicolumn{2}{|l|}{$\beta_{5}$} & \multicolumn{2}{|l|}{$\beta_{6}$} & & & & \\
\hline & Cross-s. & $\mathrm{RE}$ & Cross-s. & RE & Cross-s. & $\mathrm{RE}$ & Cross-s. & RE \\
\hline Embeddedness & 0.492 & 0.000 & 0.610 & 0.284 & 0.551 & 0.142 & 0.059 & 0.142 \\
\hline Egalitarianism & 0.516 & 0.446 & 0.395 & 0.000 & 0.456 & 0.223 & -0.060 & -0.223 \\
\hline Mastery & 0.593 & 0.636 & 0.000 & 0.000 & 0.297 & 0.318 & -0.297 & -0.318 \\
\hline \multicolumn{9}{|c|}{ Without contiguity and common official language } \\
\hline Embeddedness & 0.829 & 0.691 & 0.640 & 0.514 & 0.735 & 0.603 & -0.095 & -0.089 \\
\hline Egalitarianism & 0.595 & 0.520 & 0.435 & 0.000 & 0.515 & 0.260 & -0.080 & -0.260 \\
\hline Mastery & 0.852 & 0.866 & 0.000 & 0.000 & 0.426 & 0.433 & -0.426 & -0.433 \\
\hline
\end{tabular}

Standardized betas (the coefficients divided by the standard deviation of the cultural variable in question) are calculated from Tables 3 and $4 ; \beta_{\text {lev }}$ and $\beta_{\text {dist }}$ are calculated by using Eqs. (2) and (3) in Sect. 3 and rounded to three decimals

embeddedness [roughly the difference between Singapore (4.62) and Brazil (4.01)] is predicted not to affect FDI (statistically significantly) or to increase FDI by $28.4 \%$ depending on the sign of the cultural distance. Making use of Eqs. (2) and (3), this implies a level effect of $14.2 \%$ and an equally large and positive distance effect. As for egalitarianism, one standard deviation increase in egalitarianism [about the difference between the USA (5.110) and Russia (4.631)] is associated with a $22.3 \%$ increase in FDI as a result of an increase in its level and the same increase in FDI as a result of the decrease in egalitarianism distance between the two countries. In the case of mastery, one standard deviation increase in mastery [roughly equivalent to the difference between the USA (4.234) and Germany (3.720)] is predicted to attract $31.8 \%$ more FDI resulting from a higher level of mastery and to attract the same percent (statistically insignificant) more FDI as a result of a decrease in the distance.

The cross-section estimates do not tell us a radically different story, but imply different relative sizes of the two effects. The level effects of embeddedness and egalitarianism are estimated to be more important than their distance effects. As for the mastery, the cross section numbers are very similar to the random effects ones.

So, our results evidence that the level effect is generally stronger than the distance effect: embeddedness does not have any of the latter, the distance effect of egalitarianism is very much dependent on the estimation method applied, but it is very probably much more substantial than that of embeddedness. Mastery very clearly has a distance effect, about as large as its level effect. All this means that what we have hypothesized in Sect. 4 has been largely evidenced. On the one hand, destination countries with "better" values attract more FDI than other destination countries with worse cultural values because, as explained in Sect. 4, all the three cultural values contribute to cheaper, smoother rule compliance and cooperation with stakeholders in the destination country. On the other hand, it seems that investors prefer a destination country with less cultural difference from their home country to another destination country that is culturally farther from the investor's country, which is plausible and is in line with the findings of the literature. 


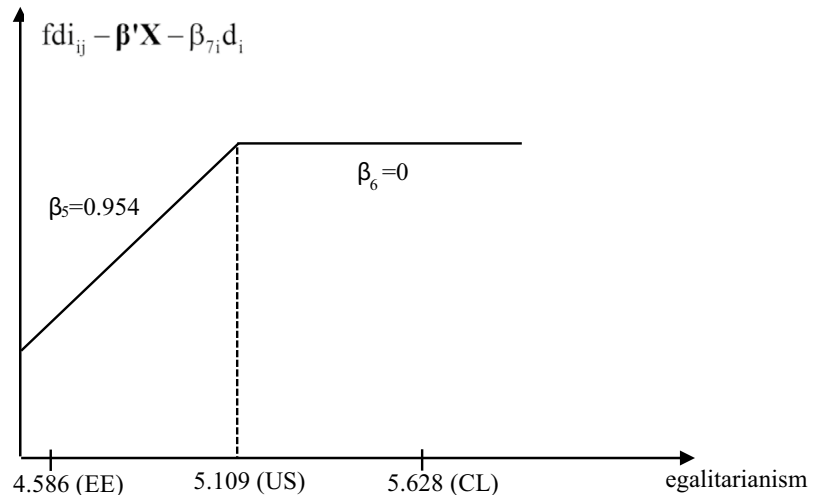

Fig. 1 Level vs distance effect of egalitarianism

One concern that may arise about these results, especially as regards the small distance effect, is that it proves to be smaller than it really is because a large part of it is already accounted for by the common official language and contiguity variables. To check this possibility we re-ran the regressions in Tables 3 and 4 without these two explanatory variables. The lower panel of Table 6 shows the standardized betas and the two effects calculated from these regressions. The main conclusion concerning the size of the distance effect relative to the level effect remains roughly unchanged. It is the level effect, if any, that seems even larger now.

To illustrate our results and make them somewhat less abstract, let us take the United States as the origin country to interpret the estimations regarding the effect of egalitarianism from RE IV regression in Table $4 . \beta_{5}$ and $\beta_{6}$ are estimated to be 0.954 and 0 (positive but not significant), which results in a level effect $\left(\beta_{\text {lev }}\right)$ of 0.477 and an equally large distance effect $\left(\beta_{\text {dist }}\right)$ of -0.477 . All this actually means that the extent to which a given destination country attracts more US FDI than does another depends as much on the difference between the cultures in the two destination countries as it does on the difference between their cultural distances from the US.

Let us take Chile (CL) and Estonia (EE) as two destination countries for the reason that their distances in terms of egalitarianism form the US are roughly the same $(+0.518$ and -0.524 , respectively) in absolute value, as illustrated on Fig. 1 .

The prediction then for log fdi difference between the two countries is:

$$
\begin{aligned}
\Delta \mathrm{fdi} & =\beta_{5}\left(\operatorname{cult}_{\mathrm{US}}-\operatorname{cult}_{\mathrm{EE}}\right)+\beta_{6}\left(\operatorname{cult}_{\mathrm{CL}}-\operatorname{cult}_{\mathrm{US}}\right) \\
& \left.=\beta_{l e v}\left(\operatorname{cult}_{\mathrm{CL}}-\operatorname{cult}_{\mathrm{EE}}\right)+\beta_{\mathrm{dist}}\left(\operatorname{cult}_{\mathrm{CL}}-\operatorname{cult}_{\mathrm{US}}\right)-\left(\operatorname{cult}_{\mathrm{US}}-\operatorname{cult}_{\mathrm{EE}}\right)\right] \\
& =0.477 \times(5.628-4.586)-0.477 \times[0.518-0.524] \approx 0.497+0
\end{aligned}
$$

Based on this calculation, Chile is predicted to attract $1.64\left(=\mathrm{e}^{0.497}\right)$ times as much US FDI stock as Estonia because of the higher level of egalitarianism in Chile. However, since the two countries are culturally equally distant from the US there is no effect from cultural distance. 


\section{Conclusions}

In this paper we have presented new evidence on how culture affects FDI. Our most important concerns have centered on the question of whether investors from a given country invest more or less in another country with greater cultural difference than one with a lesser cultural difference. Is the difference in FDI a result of the fact that the two destination countries have different cultures or the fact that one of them is more distant culturally from the origin country than the other? We have argued that answering this question requires that we disentangle the impact of culture, which consists of separating two effects: the level (the former) and the distance effect (the latter), which are mixed in the literature, leading in this way to biased conclusions in relation to how cultural distance matters for FDI.

Most importantly, we have proposed an econometric method to separate the two effects of culture, in which the key is that cultural distance does not depend on the origin country's culture as required by the principle of measurement equivalence in cultural distance laid down by van Hoorn and Maseland (2014). In this way, our procedure may have applications in related research areas as well, such as MNEs entry modes research.

The results of regressions using different methods, first of all, have evidenced that culture matters for FDI stocks on its own, meaning that it affects foreign investments beyond formal institutions. Secondly, we have found that the level effect of culture, i.e., the effect arising from a higher level of culture in a given destination country as compared to that in another one, irrespective of the level of culture in the origin country, is very "strong" in the sense that it is a working effect in the case of all the three cultural values and its size is economically significant, as well. According to our regressions results, the distance effect is at best as important as the level effect but very probably less so. The equal importance of the two effects can be clearly supported only for mastery. In the case of embeddedness the distance effect is either none or a very small positive one, while in the case of egalitarianism the size of distance effect depends on the estimation method, but never exceeds the size of the level effect.

To sum up, our results for the OECD countries as origin countries have demonstrated that once we correctly separate the level and the distance effects of the culture, the level effect proves to be more important, which means that when foreign investors choose between destination countries, they prefer those countries in which cultural values are "better". This finding is easy to understand on the basis of the meanings of our cultural values (see Table 2): a higher embeddedness is favorable for foreign firms because people in a high-embeddedness society are supposed to comply with rules of the firm to a greater extent than in a low-embeddedness society; a higher level of egalitarianism can lead to an easier and less costly cooperation between the foreign investors and the stakeholders; a higher mastery is favorable for foreign firms since in such an environment stakeholders put greater emphasis on reaching the goals of the company. Our findings evidence on the other hand that when choosing between two destination countries, foreign investors' decision is to a greater extent driven by the differences in the levels of culture in the two destination countries than by the differences in the two destination countries' distances from the home country. This latter may come as a surprise in the light of the literature which, clearly, has "overemphasized" the impact of cultural distance due to the biased 
empirical results arising from the lack of measurement equivalence as identified by van Hoorn and Maseland (2014).

However, we do not intend to generalize our findings. Firstly, because our origin countries include only OECD countries, and secondly, because our concern here has been on the impact of the "deep" cultural values, and the fact that cultural distance matters to a lesser extent does not necessarily imply that it does not matter more for different cultural dimensions. We think however that further work on this field of inquiry should be based on the separation of the two effects of culture.

Acknowledgements Open access funding provided by University of Debrecen (DE). This paper has been supported by the National Research, Development and Innovation Office of Hungary (Project number: K 120686).

\section{Compliance with ethical standards}

Conflict of interest The authors declare that they have no conflict of interest.

Open Access This article is licensed under a Creative Commons Attribution 4.0 International License, which permits use, sharing, adaptation, distribution and reproduction in any medium or format, as long as you give appropriate credit to the original author(s) and the source, provide a link to the Creative Commons licence, and indicate if changes were made. The images or other third party material in this article are included in the article's Creative Commons licence, unless indicated otherwise in a credit line to the material. If material is not included in the article's Creative Commons licence and your intended use is not permitted by statutory regulation or exceeds the permitted use, you will need to obtain permission directly from the copyright holder. To view a copy of this licence, visit http://creativecommons.org/licenses/by/4.0/.

\section{Appendix: A formal derivation of the level and distance effect of culture in bilateral FDI stock}

The initial assumption is that, in addition to other variables (X), FDI depends on the culture of the origin country (cult $\mathrm{j}_{\mathrm{i}}$, the culture of the destination country (cult $\mathrm{j}_{\mathrm{j}}$ ), and the cultural distance between the two countries ( dist $_{\mathrm{ij}}$ ). Formally:

$$
\mathrm{fdi}_{\mathrm{ij}}=\mathrm{f}\left(\mathbf{X}, \text { cult }_{\mathrm{i}}, \text { cult }_{\mathrm{j}}, \text { dist }_{\mathrm{ij}}\right)
$$

where

$$
\text { dist }_{\mathrm{ij}}=\mathrm{d}\left(\text { cult }_{\mathrm{i}}, \text { cult }_{\mathrm{j}}\right)
$$

with

$$
\left.\frac{\partial \mathrm{d}\left(\text { cult }_{\mathrm{i}}, \text { cult }_{\mathrm{j}}\right)}{\partial \text { cult }_{\mathrm{i}}}\right|_{\text {cult }_{\mathrm{i}}>\text { cult }_{\mathrm{j}}}>0,\left.\frac{\partial \mathrm{d}\left(\text { cult }_{\mathrm{i}}, \text { cult }_{\mathrm{j}}\right)}{\partial \text { cult }_{\mathrm{i}}}\right|_{\text {cult }_{\mathrm{i}}<\text { cult }_{\mathrm{j}}}=-\left.\frac{\partial \mathrm{d}\left(\text { cult }_{\mathrm{i}}, \text { cult }_{\mathrm{j}}\right)}{\partial \text { cult }_{\mathrm{i}}}\right|_{\text {cult }_{\mathrm{i}}>\text { cult }_{\mathrm{j}}}<0,
$$

and

$$
\left.\frac{\partial \mathrm{d}\left(\text { cult }_{\mathrm{i}}, \text { cult }_{\mathrm{j}}\right)}{\partial \text { cult }_{\mathrm{j}}}\right|_{\text {cult }_{\mathrm{i}}>\text { cult }_{\mathrm{j}}}<0,\left.\frac{\partial \mathrm{d}\left(\text { cult }_{\mathrm{i}}, \text { cult }_{\mathrm{j}}\right)}{\partial \text { cult }_{\mathrm{j}}}\right|_{\text {cult }_{\mathrm{i}}<\text { cult }_{\mathrm{j}}}=-\left.\frac{\partial \mathrm{d}\left(\text { cult }_{\mathrm{i}}, \text { cult }_{\mathrm{j}}\right)}{\partial \text { cult }_{\mathrm{j}}}\right|_{\text {cult }_{\mathrm{i}}>\text { cult }_{\mathrm{j}}}>0
$$


That is, there are two reasons why a different cult ${ }_{\mathrm{j}}$ may imply a different level of FDI with a given cult $t_{i}$. First, because a country with a culture more attractive to FDI, will attract more FDI from any country including country $i$. Second, a different cult $\mathrm{j}_{\mathrm{j}}$ may mean a different cultural distance which may also have a negative or a positive effect on FDI. The level and the distance effect can then be derived by taking the first derivative of the function defined by Eq. (6) with respect to cult $\mathrm{j}$ :

$$
\frac{\partial \mathrm{fdi}_{\mathrm{ij}}}{\partial \text { cult }_{\mathrm{j}}}=\underbrace{\frac{\partial \mathrm{f}\left(\mathbf{X}, \text { cult }_{\mathrm{i}}, \text { cult }_{\mathrm{j}}, \text { dist }_{\mathrm{ij}}\right)}{\partial \text { cult }_{\mathrm{j}}}}_{\text {level effect }}+\underbrace{\frac{\partial \mathrm{f}\left(\mathbf{X}, \text { cult }_{\mathrm{i}}, \text { cult }_{\mathrm{j}}, \text { dist }_{\mathrm{ij}}\right)}{\partial \text { dist }_{\mathrm{ij}}}}_{\text {distance effect }} \frac{\partial \mathrm{d}\left(\text { cult }_{\mathrm{i}}, \text { cult }_{\mathrm{j}}\right)}{\partial \text { cult }_{\mathrm{j}}}
$$

which means that the size of this derivative depends on the relation between cult $_{\mathrm{i}}$ and cult $t_{\mathrm{j}}$. Using the assumptions (7) and (8) we get the following:

$$
\begin{aligned}
& \left.\frac{\partial \mathrm{fdi}_{\mathrm{ij}}}{\partial \text { cult }_{\mathrm{j}}}\right|_{\text {cult }_{\mathrm{i}}>\text { cult }_{\mathrm{j}}}=\frac{\partial \mathrm{f}\left(\mathbf{X}, \text { cult }_{\mathrm{i}}, \text { cult }_{\mathrm{j}}, \text { dist }_{\mathrm{ij}}\right)}{\partial \text { cult }_{\mathrm{j}}}-\left.\frac{\partial \mathrm{f}\left(\mathbf{X}, \text { cult }_{\mathrm{i}}, \text { cult }_{\mathrm{j}}, \text { dist }_{\mathrm{ij}}\right)}{\partial \text { dist }_{\mathrm{ij}}} \frac{\partial \mathrm{d}\left(\text { cult }_{\mathrm{i}}, \text { cult }_{\mathrm{j}}\right)}{\partial \text { cult }_{\mathrm{j}}}\right|_{\text {cul }_{\mathrm{i}}<\text { cult }_{\mathrm{j}}} \\
& \left.\frac{\partial \mathrm{fdi}_{\mathrm{ij}}}{\partial \text { cult }_{\mathrm{j}}}\right|_{\text {cult }_{\mathrm{i}}<\text { cult }_{\mathrm{j}}}=\frac{\partial \mathrm{f}\left(\mathbf{X}, \text { cult }_{\mathrm{i}}, \text { cult }_{\mathrm{j}}, \text { dist }_{\mathrm{ij}}\right)}{\partial \text { cult }_{\mathrm{j}}}+\left.\frac{\partial \mathrm{f}\left(\mathbf{X}, \text { cult }_{\mathrm{i}}, \text { cult }_{\mathrm{j}}, \text { dist }_{\mathrm{ij}}\right)}{\partial \text { dist }_{\mathrm{ij}}} \frac{\partial \mathrm{d}\left(\text { cult }_{\mathrm{i}}, \text { cult }_{\mathrm{j}}\right)}{\partial \text { cult }_{\mathrm{j}}}\right|_{\text {cult }_{\mathrm{i}}<\text { cult }_{\mathrm{j}}}
\end{aligned}
$$

These two equations allow us to derive the two effects by comparing the effect of cult $_{\mathrm{j}}$ on FDI with positive (cult $\mathrm{j}_{\mathrm{j}}>$ cult $_{\mathrm{i}}$ ) and negative $\left(\right.$ cult $_{\mathrm{j}}<$ cult $_{\mathrm{i}}$ ) cultural distance. The level effect is

$$
\frac{\partial \mathrm{f}\left(\mathbf{X}, \text { cult }_{\mathrm{i}}, \text { cult }_{\mathrm{j}}, \text { dist }_{\mathrm{ij}}\right)}{\partial \text { cult }_{\mathrm{j}}}=\frac{1}{2}\left[\left.\frac{\partial \mathrm{fdi}_{\mathrm{ij}}}{\partial \text { cult }_{\mathrm{j}}}\right|_{\text {cult }_{\mathrm{i}}>\text { cult }_{\mathrm{j}}}+\left.\frac{\partial \mathrm{fdi}_{\mathrm{ij}}}{\partial \text { cult }_{\mathrm{j}}}\right|_{\text {cult }_{\mathrm{i}}<\text { cult }_{\mathrm{j}}}\right]
$$

while the distance effect is

$$
\frac{\partial \mathrm{f}\left(\mathbf{X}, \text { cult }_{\mathrm{i}}, \text { cult }_{\mathrm{j}}, \text { dist }_{\mathrm{ij}}\right)}{\partial \text { dist }_{\mathrm{ij}}}=\frac{1}{2}\left[\left.\frac{\partial \mathrm{fdi}_{\mathrm{ij}}}{\partial \text { cult }_{\mathrm{j}}}\right|_{\text {cul }_{\mathrm{i}}<\text { cult }_{\mathrm{j}}}-\left.\frac{\partial \mathrm{fdi}_{\mathrm{ij}}}{\partial \text { cult }_{\mathrm{j}}}\right|_{\text {cult }_{\mathrm{i}}<\text { cult }_{\mathrm{j}}}\right]\left(\left.\frac{\partial \mathrm{d}\left(\text { cult }_{\mathrm{i}}, \text { cult }_{\mathrm{j}}\right)}{\partial \text { cult }_{\mathrm{j}}}\right|_{\text {cult }_{\mathrm{i}}<\text { cult }_{\mathrm{j}}}\right)^{-1}
$$

In order to arrive at a tractable econometric specification we specify Eq. (6) to be linear:

$$
\mathrm{fdi}_{\mathrm{ij}}=\boldsymbol{\beta}^{\prime} \mathbf{X}+\beta_{i} \text { cult }_{i}+\beta_{\text {lev }} \text { cult }_{\mathrm{j}}+\beta_{\text {dist }} \mid \text { cult }_{\mathrm{i}}-\text { cult }_{\mathrm{j}} \mid
$$

where $\beta_{\text {lev }}$ is the level effect, $\beta_{\text {dist }}$ is the distance effect and cultural distance is defined as

$$
\operatorname{dist}_{\mathrm{ij}}=\mid \text { cult }_{\mathrm{i}}-\text { cult }_{\mathrm{j}} \mid \text {. }
$$

It is, however, more intuitive to derive the level and the distance effect by calculating the effect of cult $\mathrm{j}_{\mathrm{j}}$ depending on cult $\mathrm{i}_{\mathrm{i}}$ In addition, the interpretation of $\beta_{\text {lev }}$ 
and $\beta_{\text {dist }}$ would not be straightforward, once cult $t_{\mathrm{i}}$ were controlled for. How can dist $\mathrm{ij}_{\mathrm{ij}}$ change, if cult $t_{i}$ and cult $t_{j}$ is accounted for? To avoid the difficulty of interpretation but allowing for the control of origin country effect (including the culture of the origin country) we run regressions with the following specification:

$$
\mathrm{fdi}_{\mathrm{ij}}=\boldsymbol{\beta}^{\prime} \mathbf{X}+\beta_{5} \mathrm{ncd}_{\mathrm{ij}}\left(\text { cult }_{\mathrm{j}}-\text { cult }_{\mathrm{i}}\right)+\beta_{6} \text { pcd }_{\mathrm{ij}}\left(\text { cult }_{\mathrm{j}}-\text { cult }_{\mathrm{i}}\right)+\beta_{7 \mathrm{i}} \mathrm{d}_{\mathrm{i}}
$$

where

$$
\begin{aligned}
& \operatorname{ncd}_{\mathrm{ij}}=\left\{\begin{array}{lc}
1, & \text { if cult } \mathrm{j}_{\mathrm{j}} \leq \text { cult }_{\mathrm{i}}, \\
0, & \text { otherwise }
\end{array}\right. \\
& \operatorname{pcd}_{\mathrm{ij}}=\left\{\begin{array}{lc}
1, & \text { if cult } \mathrm{j}_{\mathrm{j}}>\text { cult }_{\mathrm{i}}, \\
0, & \text { otherwise, }
\end{array}\right.
\end{aligned}
$$

where

$$
\beta_{7 \mathrm{i}}=\left(\beta_{\mathrm{i}}+\frac{\beta_{5}+\beta_{6}}{2}\right) \text { cult }_{\mathrm{i}}, \quad \beta_{5}=\beta_{\text {lev }}-\beta_{\mathrm{dist}}, \quad \beta_{6}=\beta_{\text {lev }}+\beta_{\mathrm{dist}},
$$

and $d_{i}$ is the dummy of origin country $i$.

To see that the specification in Eq. (14) is equivalent with that of Eqs. (16)-(19), consider that according to Eqs. (16)-(19)

$$
\begin{aligned}
\text { fdi }_{\mathrm{ij}} & =\boldsymbol{\beta}^{\prime} \mathbf{X}+\beta_{5} \text { cult }_{\mathrm{j}}+\left(\beta_{\mathrm{i}}+\frac{\beta_{6}-\beta_{5}}{2}\right) \text { cult }_{\mathrm{i}}=\boldsymbol{\beta}^{\prime} \mathbf{X}+\left(\beta_{\text {lev }}-\beta_{\text {dist }}\right) \text { cult }_{\mathrm{j}}+\left(\beta_{i}+\beta_{\mathrm{dist}}\right) \text { cult }_{\mathrm{i}} \\
& \left.=\boldsymbol{\beta}^{\prime} \mathbf{X}+\beta_{\mathrm{i}} \text { cult }_{\mathrm{i}}+\beta_{\text {lev }} \text { cult }_{\mathrm{j}}+\beta_{\text {dist }} \text { cult }_{\mathrm{j}}-\text { cult }_{\mathrm{i}}\right)
\end{aligned}
$$

if cult cult $_{\mathrm{i}}$; and

$$
\begin{aligned}
\text { fdi }_{i j}= & \boldsymbol{\beta}^{\prime} \mathbf{X}+\beta_{6} \text { cult }_{j}+\left(\beta_{\mathrm{i}}-\frac{\beta_{6}-\beta_{5}}{2}+\right) \text { cult }_{\mathrm{i}}=\boldsymbol{\beta}^{\prime} \mathbf{X}+\left(\beta_{\text {lev }}+\beta_{\text {dist }}\right) \text { cult }_{\mathrm{j}}+\left(\beta_{\mathrm{i}}-\beta_{\mathrm{dist}}\right) \text { cult }_{\mathrm{i}} \\
& =\boldsymbol{\beta}^{\prime} \mathbf{X}+\beta_{\mathrm{i}} \text { cult }_{\mathrm{i}}+\beta_{\text {lev }} \text { cult }_{\mathrm{j}}-\beta_{\mathrm{dist}}\left(\text { cult }_{\mathrm{j}}-\text { cult }_{\mathrm{i}}\right)
\end{aligned}
$$

if cult $\mathrm{j}_{\mathrm{j}}>$ cult $_{\mathrm{i}}$.

Equations (20) and (21) together mean that the specification in Eqs. (16)-(19) is equivalent with the specification in Eq. (14). This is to say that the level and the distance effects depend on the relative size of $\beta_{6}$ and $\beta_{5}$ in the following way:

$$
\begin{aligned}
& \beta_{\mathrm{lev}}=\frac{1}{2}\left(\beta_{5}+\beta_{6}\right) \\
& \beta_{\mathrm{dist}}=\frac{1}{2}\left(\beta_{6}-\beta_{5}\right)
\end{aligned}
$$

Definitions and summary statistics of our variables can be found in Tables 7, 8 and 9 . 


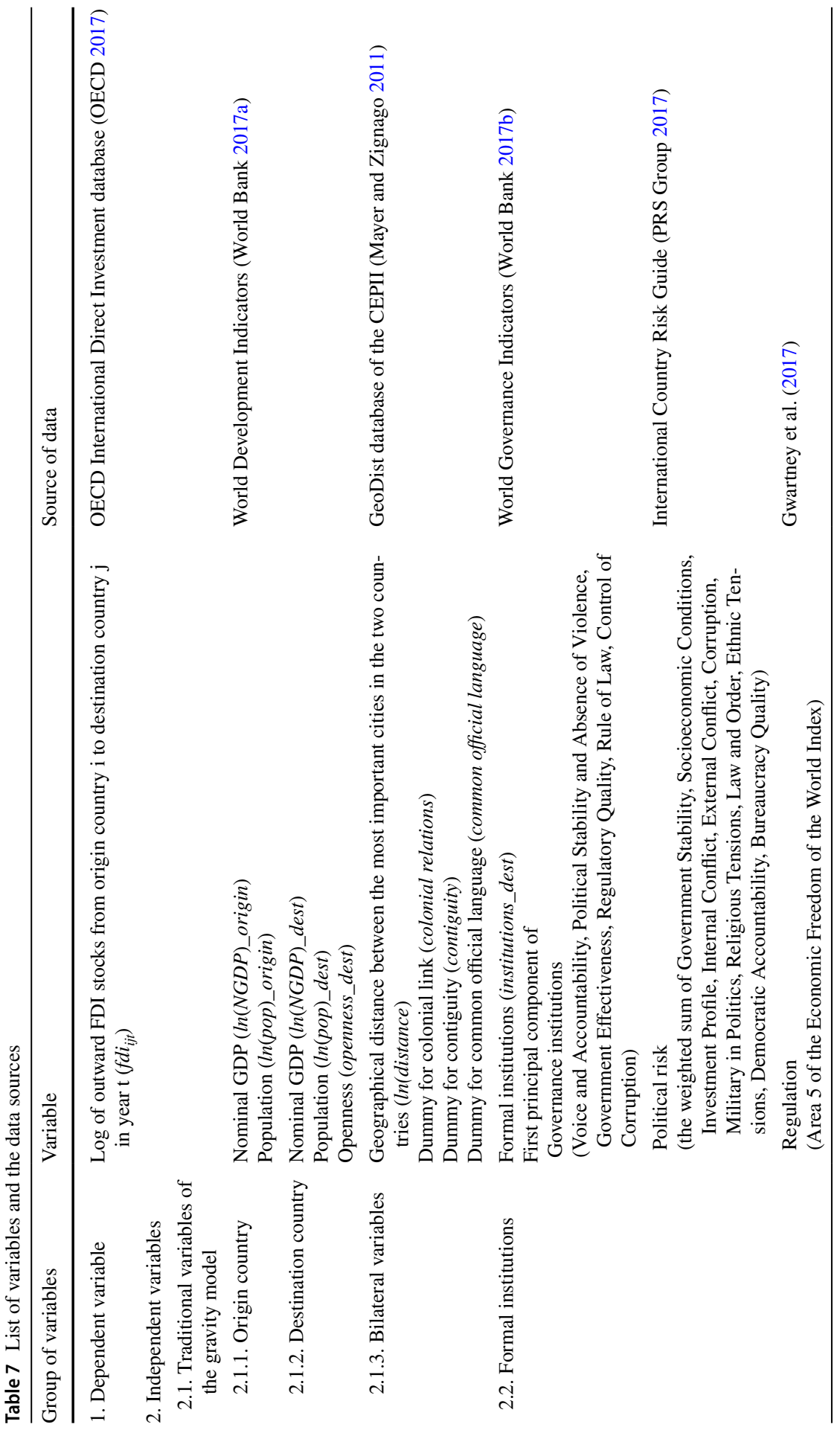




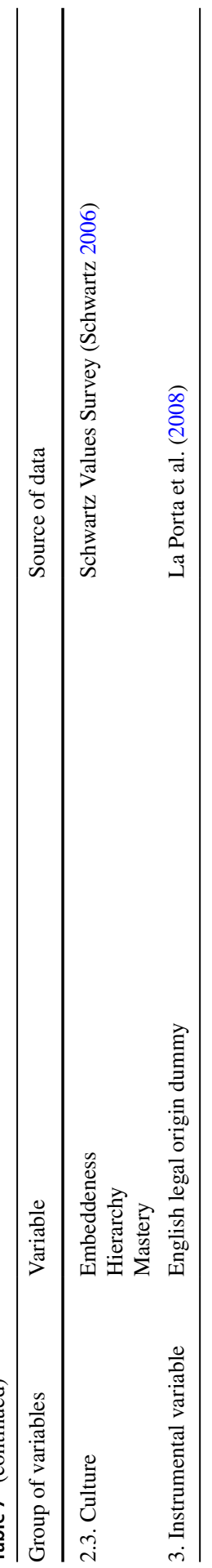


Table 8 Correlation between the three Schwartzian cultural values

\begin{tabular}{llll}
\hline & Embeddedness & Egalitarianism & Mastery \\
\hline Embeddedness & 1 & & \\
Egalitarianism & 0.388 & 1 & \\
Mastery & 0.764 & 0.425 & 1 \\
\hline
\end{tabular}

Number of observations (countries): 52

Table 9 Summary statistics of the panel dataset of Table 4

\begin{tabular}{|c|c|c|c|c|c|c|}
\hline Variable & Mean & s.d. & Min & Max & Countries & Obs \\
\hline \multicolumn{7}{|c|}{ Panel A: origin country variables } \\
\hline $\ln (\mathrm{NGDP})$ _origin & 26.921 & 1.412 & 23.009 & 30.413 & 31 & 322 \\
\hline $\ln ($ pop)_origin & 2.851 & 1.276 & 0.281 & 5.752 & 31 & 322 \\
\hline \multicolumn{7}{|c|}{ Panel B: destination country variables } \\
\hline ln(NGDP)_dest & 26.347 & 1.703 & 21.936 & 30.446 & 52 & 621 \\
\hline $\ln ($ pop)_dest & 3.106 & 1.599 & -0.343 & 7.217 & 52 & 621 \\
\hline openness_dest & 73.876 & 60.117 & 17.197 & 419.520 & 52 & 621 \\
\hline institutions_dest & 66.013 & 23.461 & 5.683 & 100 & 52 & 621 \\
\hline Embeddedness & 3.968 & 0.625 & 2.583 & 5.375 & 52 & 621 \\
\hline Egalitarianism & 4.978 & 0.343 & 4.103 & 5.628 & 52 & 621 \\
\hline Mastery & 3.960 & 0.403 & 3.198 & 4.941 & 52 & 621 \\
\hline Variable & Mean & s.d. & Min & $\operatorname{Max}$ & Country pairs & obs \\
\hline \multicolumn{7}{|l|}{ Panel C: country-pair variables } \\
\hline $\ln ($ distance $)$ & 8.127 & 1.120 & 4.088 & 9.875 & 1296 & 12,076 \\
\hline Contiguity & 0.067 & 0.250 & 0 & 1 & 1296 & 12,076 \\
\hline Common official language & 0.086 & 0.281 & 0 & 1 & 1296 & 12,076 \\
\hline Colonial relations & 0.054 & 0.227 & 0 & 1 & 1296 & 12,076 \\
\hline ncd ×(emb_dest-emb_or) & -0.174 & 0.334 & -1.906 & 0 & 1296 & 12,076 \\
\hline pcd $\times$ (emb_dest-emb_or) & 0.531 & 0.585 & 0 & 2.792 & 1296 & 12,076 \\
\hline ncd ×(egal_dest-egal_or) & -0.176 & 0.271 & -1.525 & 0 & 1296 & 12,076 \\
\hline pcd $\times$ (egal_dest-egal_or) & 0.201 & 0.274 & 0 & 1.280 & 1296 & 12,076 \\
\hline ncd $\times$ (mast_dest-mast_or) & -0.134 & 0.245 & -1.194 & 0 & 1296 & 12,076 \\
\hline pcd $\times$ (mast_dest-mast_or) & 0.323 & 0.362 & 0 & 1.743 & 1296 & 12,076 \\
\hline
\end{tabular}

\section{References}

Ali, F., Fiess, N., \& MacDonald, R. (2010). Do institutions matter for foreign direct investment? Open Economies Review, 21(2), 201-219.

Asiedu, E., \& Lien, D. (2011). Democracy, foreign direct investment and natural resources. Journal of International Economics, 84, 99-111.

Barassi, M. R., \& Zhou, Y. (2012). The effect of corruption on FDI: A parametric and non-parametric analysis. European Journal of Political Economy, 28, 302-312. 
Bénassy-Quéré, A., Coupet, M., \& Mayer, T. (2007). Institutional determinants of foreign direct investment. World Economy, 30(5), 764-782.

Beugelsdijk, S., \& Maseland, R. (2011). Culture in economics: History, methodological reflections and contemporary applications. Cambridge: Cambridge University Press.

Bhardwaj, A., Dietz, J., \& Beamish, P. W. (2007). Host country cultural influences on foreign direct investment. Management International Review, 47(1), 29-50.

Boettke, P. J., Coyne, C. J., \& Leeson, P. T. (2008). Institutional stickiness and the new development economics. American Journal of Economics and Sociology, 67(2), 331-358.

Busse, M. (2004). Transnational corporations and repression of political rights and civil liberties: An empirical analysis. Kyklos, 57(1), 45-65.

Busse, M., \& Hefeker, C. (2007). Political risk, institutions and foreign direct investment. European Journal of Political Economy, 23(2), 397-415.

Daude, C., \& Stein, E. (2007). The quality of institutions and foreign direct investment. Economics and Politics, 19(3), 317-344.

Du, J., Lu, Y., \& Tao, Z. (2012). Institutions and FDI location choice: The role of cultural distances. Journal of Asian Economics, 23, 210-223.

Durlauf, S. N., \& Fafchamps, M. (2005). Social capital. In P. Aghion \& S. N. Durlauf (Eds.), Handbook of economic growth (Vol. 1B, pp. 1639-1699). Amsterdam: North-Holland.

Globerman, S., \& Shapiro, D. (2002). Global foreign direct investment flows: The role of governance infrastructure. World Development, 30(11), 1899-1919.

Grosse, R., \& Trevino, L. J. (1996). Foreign direct investment in the United States: An analysis by country of origin. Journal of International Business Studies, 27(1), 139-155.

Gwartney, J., Lawson, R., \& Hall, J. (2017). Economic freedom of the World 2017 Annual Report. Vancouver: The Fraser Institute.

Habib, M., \& Zurawicki, L. (2002). Corruption and foreign direct investment. Journal of International Business Studies, 33(2), 291-293.

Hofstede, G. (1980). Culture's consequences: International differences in work-related values. Beverly Hills, CA: Sage Publications.

Hofstede, G. (2001). Culture's consequences: Comparing values, behaviors, institutions and organizations across nations. Beverly Hills, CA: Sage Publications.

Holmes, R. M., Miller, T., Hitt, M. A., \& Salmador, M. P. (2013). The interrelationships among informal institutions, formal institutions, and inward foreign direct investment. Journal of Management, 39, 531-566.

House, R. J., Hanges, P. J., Javidan, M., Dorfman, P. W., \& Gupta, V. (2004). Culture, leadership and organization: The globe study of 62 societies. Thousands Oaks, CA: SAGE Publications.

Kapás, J. (2020). Formal and informal institutions, and FDI flows: A review of the empirical literature and propositions for further research. Economic and Business Review (forthcoming).

Klasing, M. (2013). Cultural dimensions, collective values and their importance for institutions. Journal of Comparative Economics, 41(2), 447-467.

Kogut, B., \& Singh, H. (1988). The effect of national culture on the choice of entry mode. Journal of International Business Studies, 19(3), 411-432.

Kurul, Z. (2017). Nonlinear relationship between institutional factors and FDI flows: Dynamic panel threshold analysis. International Review of Economics and Finance, 48, 148-160.

La Porta, R., Lopez-de-Silanes, F., \& Shleifer, A. (2008). The economic consequences of legal origin. Journal of Economic Literature, 46(2), 258-332.

Li, Q., \& Resnick, A. (2003). Reversal of fortunes: Democratic institutions and foreign direct investment inflows to developing countries. International Organization, 57(1), 175-211.

Lucke, N., \& Eichler, S. (2016). Foreign direct investment: The role of institutional and cultural determinants. Applied Economics, 48(11), 935-956.

Mayer, T., \& Zignago, S. (2011). Notes on CEPII's distances measures: The GeoDist database. CEPII Working Paper 2011-25.

Mondolo, J. (2019). How do informal institutions influence inward FDI? A systematic review. Economia Politica, 36(1), 167-204.

OECD. (2017). FDI positions by partner country. http://stats.oecd.org/index.aspx? DataSetCode=FDI_ POSITION_PARTNER.

Plümper, T., \& Troeger, V. E. (2007). Efficient estimation of time-invariant and rarely changing variables in finite sample panel analyses with unit fixed effects. Political Analysis, 15, 124-139.

PRS Group. (2017). International Country Risk Guide: Researcher's Dataset. 
Schwartz, S. H. (1999). A theory of cultural values and some implications for work. Applied Psychology: An International Review, 48(1), 23-47.

Schwartz, S. H. (2006). A theory of cultural value orientations: Explication and applications. Comparative Sociology, 5(2-3), 137-182.

Seyoum, B. (2011). Informal institutions and foreign direct investment. Journal of Economic Issues XLV, 4, 917-940.

Siegel, J. I., Licht, A. N., \& Schwartz, S. H. (2012). Egalitarianism, cultural distance, and foreign direct investment: A new approach. Organization Science, 24(4), 1174-1194.

Slangen, A. H. L., \& Beugelsdijk, S. (2010). The impact of institutional hazards on foreign multinational activity: A contingency perspective. Journal of International Business Studies, 41(6), 980-995.

Tabellini, G. (2010). Culture and institutions. Economic development in the regions of Europe. Journal of the European Economic Association, 8(4), 677-716.

Tang, L. (2012). The direction of cultural distance on FDI: Attractiveness or incongruity? Cross Cultural Management: An International Journal, 19(2), 233-256.

van Hoorn, A., \& Maseland, R. (2014). Is distance the same across cultures? A measurement-equivalence perspective on the cultural distance paradox. In A. Verbeke, R. van Tulder, \& S. Lundan (Eds.), Multinational enterprises, markets and institutional diversity. Progress in international business research (Vol. 9, pp. 207-227). Bingley: Emerald Group Publishing Limited.

van Hoorn, A., \& Maseland, R. (2016). How institutions matter for international business: Institutional distance effects vs institutional profile effects. Journal of International Business Studies, 47(3), 374-381.

Williamson, O. E. (2000). The new institutional economics: Taking stock, looking ahead. Journal of Economic Literature, XXXVIII, 595-613.

World Bank. (2017a). World development indicators. http://datatopics.worldbank.org/world-developmen t-indicators/.

World Bank. (2017b). The worldwide governance indicators. http://info.worldbank.org/governance/wgi/ index.aspx\#home.

Publisher's Note Springer Nature remains neutral with regard to jurisdictional claims in published maps and institutional affiliations. 